\title{
Deuda, trabajo y coerción. Las experiencias de colonización canaria en el Estado Oriental del Uruguay (1830-1843)/
}

\author{
Debt, Labor and Coercion. The Experiences of Canary \\ Colonization in the Estado Oriental del Uruguay (1830-1843)
}

Florencia Thul Charbonnier

ORCID iD: http://orcid.org/0000-0002-5740-2735

Universidad de la República, Uruguay

\begin{abstract}
Este artículo pretende analizar las experiencias de colonización canaria impulsadas por particulares y con respaldo del Estado uruguayo durante la década de 1830. Se trata de un tipo especial de inmigración, ya que los individuos firmaban un contrato que los obligaba a permanecer trabajando en Uruguay hasta saldar la deuda de su pasaje desde Europa. El Estado, a través de la policía, actuaba como garante del cumplimiento de los contratos.

Palabras Clave: Inmigración; Canarias; Coacción; Deuda; Contratos de trabajo.

This article analyzes the experiences of colonization from the Canary Islands driven by private entrepreneurs and backed by the Uruguayan State during the 1830s. This was a special type of immigration, close to indenture servitude, where individuals moving across the continents signed a contract that forced them to keep working in Uruguay until the debt they had incurred (the cost of their maritime passage) was repaid. The Uruguayan State, through the police, was both the guarantor and enforcer of these contracts.
\end{abstract}

KeYwords: Inmigration; Canarias; Coercion, Debt, Employment Contracts.

Copyright: (C 2017 CSIC. Este es un artículo de acceso abierto distribuido bajo los términos de una licencia de uso y distribución Creative Commons Attribution (CC-by) España 3.0. 


\section{Introducción}

En 1838 Manuela Gordillo y su hijo Francisco Suárez partieron desde Las Palmas de Gran Canaria con destino a Montevideo a bordo de la corbeta Bella Julia, al mando del capitán Juan José de Soria. Juan María Pérez, arrendatario del viaje, se hizo acreedor de la deuda generada por concepto de los dos pasajes, que ascendía a un total de 250 pesos. Desde el 6 de marzo de 1839, tanto la mujer como su hijo fueron contratados por Carlos Parco, quien tras la firma de un contrato con Pérez se hizo cargo de la deuda a cambio de contar con los servicios de ambos. Manuela y Francisco quedarían empleados bajo las órdenes de Parco hasta que saldaran su deuda y en caso de no hacerlo, la policía capitalina podía intervenir para obligarlos a pagar o regresarlos a la casa de Pérez.

El caso de esta madre y su hijo fue solo uno de los que se repitieron en la década de 1830 en el recientemente creado Estado uruguayo. Por iniciativa privada y bajo control estatal se produjo un tipo especial de colonización que involucró a individuos de las islas Canarias. Los colonos desembarcaban desde Europa con una deuda por sus pasajes que debían afrontar con su trabajo una vez arribados a destino. En un contrato se estipulaba el valor de la deuda y el salario a percibir, además de la precisión de que no podían abandonar su trabajo hasta no saldar lo adeudado. Estos varones y mujeres canarias decidían contratarse para hacer el viaje, pero eran objeto de coerción una vez llegados a Montevideo en pos del cumplimiento del contrato que habían firmado.

El Estado Oriental del Uruguay fue creado por una Asamblea constituyente en 1829. Un año antes se había firmado un tratado de paz entre el Imperio del Brasil y las Provincias Unidas del Río de la Plata, mediante el cual la independencia de estos territorios fue reconocida. Uruguay se sitúa en la franja norte del Río de la Plata, limitando al oeste con Argentina y al noreste con Brasil. Parte de esta zona fue denominada durante el dominio colonial español como Banda Oriental e integraba la región del Río de la Plata que comenzó su proceso hacia la independencia en 1810, tras la crisis del imperio español en el marco de las guerras napoleónicas.

Luego de dos décadas de guerras por la independencia y de grandes penurias económicas, el Estado uruguayo debió enfrentar un problema central: la escasez de población y de mano de obra. Para intentar combatirlo, el Estado y los particulares ensayaron dos prácticas complementarias: la atracción de mano de obra desde el extranjero y el disciplinamiento de la 
fuerza de trabajo disponible en el país. Los planes de colonización canaria fueron parte de estas estrategias impulsadas durante la década de 1830 en pos de equiparar la oferta con la creciente demanda de mano de obra ante la tendencia de mejora de las condiciones económicas.

Este artículo propone describir y analizar la colonización canaria al Uruguay durante la década de 1830. El tema se inserta en la discusión historiográfica sobre los sistemas de trabajo compulsivos y su vínculo con la inmigración a América Latina. Las fuentes a utilizar serán diversas: documentación proveniente del archivo del empresario montevideano Juan María Pérez, uno de los principales protagonistas de esta empresa; leyes, decretos, reglamentos y resoluciones del gobierno; documentos de la Jefatura de Policía de la capital; censos o padrones de población.

\section{Antecedentes}

Los estudios de migración española a Uruguay son diversos y se nutren de las historiografías de diferentes países. Específicamente sobre los inmigrantes canarios, los trabajos provienen tanto de Uruguay como de España.

Uno de los primeros autores en estudiar la inmigración a Uruguay en la década de 1830 fue Juan Oddone (1966), quien la definió como una etapa del proceso inmigratorio marcado por el accionar privado y con poca intervención estatal. Para el autor, este tráfico «tendía a asimilarse a las formas operativas del antiguo comercio negrero». ${ }^{1}$

El historiador uruguayo Juan E. Pivel Devoto plantea que los primeros gobiernos constitucionales impulsaron medidas para fomentar la producción agrícola y la inmigración y así resolver el principal problema que obstaculizaba su desarrollo: la escasez de brazos. De acuerdo al autor, las medidas del gobierno para atraer población extranjera no fueron efectivas dada la inexistencia de un ordenado plan de colonización. Identifica, sí, una serie de iniciativas privadas para la atracción de población canaria, como fueron los casos de Samuel Lafone y Juan María Pérez. ${ }^{2}$

Otros aportes, desde los años ochenta, fueron los de Luis Musso y Nelson Martínez. Ambos autores han abordado la cuestión desde múltiples perspectivas (historiográfica, social, política) y marcos temporales (período

1 Oddone, 1966, 103.

2 Pivel Devoto, 1972, XXXVII. 
colonial, independiente, finales del siglo XIX). Han consultado fuentes de diversa procedencia, tanto en Uruguay como en España.

También la historiografía canaria se ha dedicado a abordar la migración hacia Uruguay, aunque de acuerdo a Carnero y Barroso (2006) es todavía uno de los aspectos menos estudiados de este movimiento en su conjunto. Al respecto pueden señalarse los aportes de Enrique Guerrero (1960), María Cristina Albelo (1985), Manuel de Paz y Manuel Hernández (1993), Francisco Cerdeña (2002) y los ya citados Fernando Carnero y Cristino Barroso (2006). Tanto estos autores como los uruguayos han señalado que una de las características de esta migración era la existencia de «contratas», sistema que implicaba una relación de colonato del emigrante canario con los empresarios, de manera que debían pagar el precio del viaje, quedando los colonos en una situación de explotación económica y casi de servidumbre. Sistema que no solo fue propio del caso uruguayo sino también de otros destinos como Venezuela y Cuba. ${ }^{3}$

En cuanto a la historiografía norteamericana latinoamericanista, son muy pocos los títulos sobre la migración española a América Latina anterior a 1850. Se destaca el aporte de Parsons (1983) y los de Ida Altman (1988 y 1991).

\section{Inmigrantes «por contrato»}

La situación de los colonos canarios que aquí analizamos puede ser comparada con otras modalidades de trabajo extendidas en América desde el siglo XVII.

Una de ellas es la experiencia de la «servidumbre por contrato» (indentured servitude) extendida en Estados Unidos desde cerca de 1620. De acuerdo al economista norteamericano Farley Grubb (1985) la «servidumbre por contrato» jugó un papel de importancia en la migración europea a Estados Unidos en los siglos XVII y XVIII. ${ }^{4}$ En este sistema, los inmigrantes eran llevados desde Europa a Norteamérica mediante intermediarios a los que les debían el costo del pasaje y tenían que trabajar para ellos o para quien comprara su trabajo hasta saldar su deuda. El principal atractivo de esta empresa estaba en la posibilidad de los migrantes de obtener tierras en

3 Uno de los principales aportes respecto al sistema de «contratas» para Cuba, Venezuela y Uruguay es el artículo de Albelo, 1985.

4 Puede verse un exhaustivo trabajo sobre lo ocurrido en Virginia, EE.UU, desde el siglo XVII en Morgan, 2009. 
Norteamérica, a las que no tenían acceso en Inglaterra. Esta es una diferencia importante respecto al caso de los trabajadores canarios que llegaban a Uruguay ya que estos no obtuvieron tierras. ${ }^{5}$

Según el historiador norteamericano David Galenson (1984) uno de los principales problemas de la Compañía de Virginia era el reclutamiento y motivación de la fuerza de trabajo. La solución institucional encontrada para esto fue la implementación de la «servidumbre por contrato» experiencia que ya tenía sus años funcionando en Inglaterra para contratar mano de obra rural. De acuerdo al mismo autor las condiciones de trabajo eran duras y generaban una situación de extremo control para los migrantes. ${ }^{6}$

Para la década de 1830, la bibliografía disponible nos permite afirmar que el caso de Uruguay no fue un caso aislado. Veamos algunas experiencias similares en Cuba, Venezuela y Argentina a mediados del siglo XIX.

En 1836, la Real Junta de Comercio de Cuba solicitó operarios para la construcción de un «camino de hierro». La respuesta dada por las autoridades del archipiélago canario se tradujo en la serie de «contratas» que se firmaron para ello. Este contrato hacía alusión al precio del pasaje y a cómo sería abonado: «Su obligación a trabajar por cuenta de la Real Junta de Fomento será por el tiempo que tarden en reintegrar el dicho importe del pasaje y Licencia, a menos que entreguen en efectivo esa suma, en cuyo caso quedarán en libertad de trabajar por su cuenta». ${ }^{7}$ Los contratados, recibirían nueve pesos mensuales y estaban obligados a destinar un tercio de su salario al pago de la deuda.

En 1837 el poder ejecutivo de Venezuela se propuso contratar labradores para trabajar en la ciudad de Caracas. La documentación encontrada por Albelo en Canarias, da cuenta de que en estas islas se recibió la propuesta favorablemente y 89 canarios viajaron hacia América. Al igual que en el caso cubano, el contrato estipulaba que los individuos debían abonar el costo de su pasaje con un tercio del salario que percibieran, que estaba fijado en seis pesos fuertes. ${ }^{8}$

El historiador argentino Jorge Gelman (1999) plantea la situación ocurrida en la campaña de Buenos Aires a mediados de la década de 1840 con un tipo de inmigración similar a la registrada en Montevideo: los gallegos traídos a trabajar en las estancias de Juan Manuel de Rosas.

5 Grubb, 1985.

6 Galenson, 1984.

7 Citado por Albelo, 1985, 353.

8 Albelo, 1985, 361. 
Para intentar reducir los costos de la explotación, así como para garantizar la presencia permanente de trabajadores, Rosas debió recurrir a dos estrategias de atracción de mano de obra: los cautivos y los gallegos. ${ }^{9}$ Estos gallegos eran trabajadores españoles que el gobernador «importó» por su cuenta, o sea que les pagó el pasaje para que arribaran a Buenos Aires, con el compromiso de que trabajarían en sus estancias, por un salario, del cual se iría descontando el valor del pasaje hasta saldarlo y así convertirse en peones libres. El salario que recibían era menor que el que cobraban los demás peones y trabajaban más días a la semana que estos. ${ }^{10}$

Gelman plantea que a pesar de los intentos por consolidar este tipo de trabajo coactivo, en una especie de sustitución del lugar dejado por los esclavos, el éxito fue relativo. Las fuentes le permiten identificar varios casos de fugas, así como de gallegos que lograban saldar sus deudas y pedían que se les abonara el mismo salario que a todos los peones. El autor concluye diciendo que

el caso de Rosas muestra esta búsqueda bastante frenética por obtener acceso a trabajo seguro y barato, que en estas condiciones solo parece posible a través de sistemas serviles o semiserviles. Pero el ejemplo nos muestra también el fracaso de estos sistemas de trabajo coactivo, y en ello parecen estar interviniendo otro tipo de factores, que exceden ampliamente la situación de la economía y la demografía. ${ }^{11}$

Otro estudio más reciente sobre inmigración de asturianos y gallegos a Buenos Aires a mediados del XIX es el de la autora argentina De Cristóforis (2008). Plantea que fue recién después de 1852 que tanto el gobierno español como las autoridades argentinas expresaron su preocupación por lo que llama «tráfico emigratorio» e iniciaron diversos programas para su regulación y reglamentación. Hasta entonces se venía realizando bajo la responsabilidad de actores privados y bajo un laxo control estatal.

A mediados del ochocientos se incrementaron las corrientes migratorias desde el norte de España hacia Buenos Aires por el funcionamiento de diferentes mecanismos migratorios: «agentes impersonales de la emigración» («armadores», capitanes y otros intermediarios), los «llamados»y factores que facilitaron el pasaje ilegal. Los gallegos y asturianos que llegaron a Buenos Aires en las décadas de 1840 y 1850 lo hicieron a través de alguno de estos mecanismos. ${ }^{12}$ Estos agentes e intermediarios convirtieron

9 Gelman, 1999, 132.

10 Ibidem, 133.

11 Ibidem, 141.

12 De Cristóforis, 2008, 105. 
este tráfico inmigratorio en verdaderos negocios, de los que siempre salían favorecidos en detrimento de la situación de los migrantes y sus familias.

\section{La inmigración canaria a Uruguay en la década de 1830}

La colonización canaria a Uruguay tras la independencia debe situarse en un contexto de migraciones desde las islas Canarias a varios destinos americanos. Como señala la bibliografía española, Cuba y Venezuela fueron los principales países receptores de migrantes canarios en la primera mitad del siglo XIX. Uruguay, por su parte, fue el destino preferido por los originarios de las islas de Fuerteventura y Lanzarote. ${ }^{13}$

Las migraciones ocurridas hacia Uruguay a mediados del siglo XIX estuvieron marcadas por la asociación del Estado y los particulares. El historiador uruguayo Arturo Bentancur señala una primera etapa en el proceso migratorio de españoles entre 1830 y 1890 caracterizada por la diversa actividad llevada adelante tanto por los particulares como por el Estado uruguayo. Agrega que hasta 1852 se dio el dominio de la iniciativa privada y la preferencia por los canarios: «con el lucro como único motor y el individualismo como norma». ${ }^{14}$ En cuanto a esta preferencia señala que estaba dada por la cercanía geográfica, la falta de fertilidad de las tierras en las islas y la característica opuesta en la zona del Río de la Plata. A esto podrían agregarse otros dos aspectos: la conexión marítima existente entre las Canarias y Montevideo y la presencia previa de comunidades canarias en Montevideo. ${ }^{15}$

Desde 1833, las embarcaciones españolas eran admitidas en los puertos uruguayos ${ }^{16}$ y mediante un acuerdo firmado en 1837 entre el cónsul de España en Bayona y la «Casa Inglesa» de Samuel Lafone establecida en Montevideo, se aprobó el traslado de colonos canarios y vascongados a Uruguay. $^{17}$

13 Carnero y Barroso, 2006.

14 Bentancur, 1997, 28.

15 Desde 1725, cuando Felipe V aprobó mediante real cédula el poblamiento de lo que sería la ciudad de Montevideo, se autorizó el paso de familias canarias a estos territorios.

16 Durante los procesos de independencia de los territorios americanos la corona española, bajo Fernando VII, se declaró en «estado de guerra» con estos e impidió el traspaso de sus poblaciones a América. Según Guerrero, las medidas impulsadas no impidieron la inmigración española a territorios americanos. Guerrero, 1960, 494.

17 Guerrero, 1960, 495. 
Nelson Martínez (1985) transcribe el contrato celebrado entre Lafone y el Estado Oriental del Uruguay en 1837. Allí se estipula que el empresario se comprometía a traer al puerto de Montevideo a «personas industriosas y agrícolas que fomentasen las artes y la labranza». Las intenciones de Lafone eran promover el aumento de población de «este hermoso país única fuente de su engrandecimiento y prosperidad para que pueda llegar á ser un Estado, fuerte, respetable y rico». Agregaba que esta necesidad se agravaba por «las escaseces de brazos que se hace sentir en cualquier empresa industrial y también en la Agricultura». Los documentos de pago que recibía el empresario por parte del Estado (80 patacones por cada mayor de 14 años y 40 patacones por los menores) eran destinados a la compra de tierras públicas. Los colonos tenían un plazo de 24 meses para abonar el costo de su pasaje al fisco. Se agregaba que el Estado tendría preferencia para emplearlos en caso de que les fueran necesarios y que estaban exentos del servicio militar por 6 años desde su arribo. ${ }^{18}$

En cuanto a las estrategias del Estado, Oddone plantea que la acción oficial de Uruguay con respecto a la promoción de la inmigración fue limitada: «la circunstancia de carecer de un vasto territorio apto y sobre todo la indeterminación real de la tierra pública, dada su caótica situación jurídica, no favorecieron por cierto la política de concesiones y contratos por intermedio de agentes». ${ }^{19}$

Quienes llevaban adelante estas empresas migratorias se dedicaban a explotar en su provecho los desplazamientos transoceánicos. Actuaban sobre todo como intermediarios y recibían una comisión por emigrante transportado o embarcado. ${ }^{20}$

Un informe de 1838 de Pedro Lago, administrador de rentas nacionales de la isla de Lanzarote, lo define como un comercio clandestino prohibido por todo el derecho de gentes, que generaba la ruina de la agricultura y de la hacienda pública. De acuerdo a Lago, eran conducidos «artesanos e industriales con tanta abundancia como si fuesen fardos de mercancía, sin más habilitación que la muy precisa para el viaje». Agregaba que como la mayoría tenían pocos bienes, eran llevados como esclavos y encerrados en barracas hasta que se presentara quien los comprara «por el flete de cien duros que vayan a trabajar a sus haciendas: allí los tienen algunos años en

18 Martínez, 1985, 295-297.

19 Oddone, 1966,103.

20 Idem. 
los oficios mecánicos trabajando como los negros». ${ }^{21}$ Hay en su discurso una vinculación directa entre la migración de canarios y el comercio de esclavos, asemejando ambos procesos y destacando las pocas diferencias que había entre un tráfico y otro. Según este informe, los canarios conducidos eran «artesanos e industriales», aunque la historiografía que ha estudiado el tema plantea que la mayoría de los inmigrantes eran campesinos; la principal preocupación de Lago radicaba en que con este movimiento interoceánico, las islas Canarias se estaban quedando sin mano de obra.

El entonces ministro de Estado español, Narciso Heredia, agregaba en el mismo sentido: «hombres codiciosos y al mismo tiempo que declaman por moda o por sistema contra la esclavitud de los negros, están promoviendo la de los blancos; porque no es otra cosa el transportarlos a América del modo que se acostumbra». ${ }^{22}$ Ambos testimonios llevaron a que en 1838 se ordenara al jefe político de las Canarias que exigiera pasaporte para el traslado de colonos a Cuba, Puerto Rico y Filipinas, y prohibiera el tráfico hacia otros destinos americanos.

Definir los números de la colonización canaria al Uruguay en esta década resulta complejo debido a la escasa información confiable al respecto. De acuerdo a Andrés Lamas, ${ }^{23}$ entre 1835 y 1842 ingresaron un total de 8.200 canarios, siendo 4.900 varones y 3.300 mujeres. Representaban el $17 \%$ del total de los inmigrantes llegados al país en ese período. ${ }^{24}$ Es necesario tener cautela con estos números ya que se desconoce su origen. Andrés Lamas no menciona cuál es su fuente de información y por tanto no sabemos si son números de entrada de pasajeros por el puerto o de inmigración.

Nelson Martínez Díaz ha sugerido que la inmigración canaria representó entre el 16 y el $18 \%$ del total de la oleada inmigratoria en la década de 1830. Mediante un estudio del archivo de Juan María Pérez, este autor contabilizó 2.880 canarios ingresados entre 1835 y 1843 , consignados como colonos a nombre de este empresario. ${ }^{25}$

21 Cit. por Oddone, 1966, 76.

22 Cit. por Guerrero, 1960, 498.

23 Político y diplomático uruguayo nacido en Montevideo en 1817. Funcionario del Ministerio de Gobierno y Relaciones Exteriores desde 1834. Fue opositor al gobierno de Manuel Oribe, a quien combatió desde la redacción del diario El Nacional. Desde 1843 fue jefe de la Jefatura de Policía de Montevideo. Durante la llamada «Guerra Grande» (1838-1852) fue ministro de Hacienda y de Relaciones Exteriores. Fernández Saldaña, 1945, 688.

24 Lamas, 1928 (1850).

25 Martínez, 1985, 268-269. 
Los censos del período son poco precisos ya que las procedencias regionales se pierden bajo la categoría de «españoles». En el del año 1836 fueron registrados 2.710 «españoles», ${ }^{26}$ mientras que en el 1843 se identificaron 3.406 bajo esta nacionalidad y apenas 205 como «canarios». ${ }^{27}$

\section{El «negocio» de la colonización}

El archivo de Juan María Pérez permite hacer un seguimiento del circuito de este negocio desde sus etapas iniciales, que iban desde de la captación de migrantes en Europa hasta su arribo al puerto de Montevideo. ${ }^{28}$

Juan María Pérez fue un comerciante, ganadero, industrial y naviero nacido en Montevideo en 1790 y fallecido en la misma ciudad en 1845. Fue doctor en Teología por la Universidad de Charcas y participó activamente en los ejércitos artiguistas. Fue además ministro de Hacienda de la segunda presidencia constitucional del Uruguay. ${ }^{29}$

De acuerdo a Carlos Real de Azúa, fue «entre 1830 y 1840 el hombre más pudiente del país». ${ }^{30}$ Tenía 20 estancias, aunque su especialidad eran las tierras a los alrededores de Montevideo donde se dedicaba a la agricultura. Tenía panaderías y pulperías, atahonas y hornos de ladrillo y un molino hidráulico en la zona del Buceo. En 1836 tenía 80 casas en Montevideo y en 1840 percibía dos mil pesos mensuales por concepto de alquileres. Fue constructor y armador de barcos. Consignatario, barraquero y acopiador de frutos. Sus empresas de colonización le significaron solo parte de la inmensa fortuna que amasó hasta el estallido de la Guerra Grande. ${ }^{31}$

Un contrato entre Pérez, el consignatario y el dueño del bergantín sardo Dido, muestra las etapas iniciales del circuito, basadas en la captación de canarios. Las intenciones del viaje eran evidentes: se trataba de captar trabajadores, sobre todo familias, para que se integraran al sector

26 Censo de Montevideo, 1836, Archivo General de la Nación de Uruguay (AGN), Fondo Archivo Histórico, Archivo General Administrativo (AGA).

27 Padrón de Montevideo, 1843, AGN, AGA, Padrones, Libros 107, 256 y 263.

28 El Archivo de Juan María Pérez (AJMP) se encuentra en la sección Archivos Particulares (AP) del AGN; contiene más de 10 cajas que reúnen documentación de sus diversas actividades económicas, así como copias de su correspondencia. En 1836 llegaron a nombre de Juan María Pérez el bergantín Lucrecia y el Indio Oriental; en 1837 el Concordia; en 1838 el Indio Oriental, la goleta española Fortuna, la goleta Bella Julia y el bergantín Libertad; en 1839 nuevamente el Uruguay; en 1840, 1841 y 1842 el Indio Oriental (Martínez, 1985).

29 Montero Bustamante, 1945.

30 Real de Azúa, 1961, 147.

31 Ibidem, 148-149. 
productivo una vez arribados al puerto montevideano. La propuesta estaba dirigida a «familias de gente de trabajo, y poniendo cuidado especialmente que las expresadas familias sean compuestas de más hombres de trabajo o de 16 años para arriba, que de mujeres». ${ }^{32}$ Según Albelo, en tres buques arribados desde Canarias en 1838 (Bella Julia, Uruguay y Circunstancia) desembarcaron 916 colonos, siendo la mayoría de ellos grupos familiares completos y no hombres solos..$^{33}$

Las obligaciones de Juan María Pérez también quedaban pautadas en este contrato. Se comprometía a recibir la expedición y hacerse cargo de ella luego de los cuatro días hábiles del arribo «debiendo serle entregados los colonos en el muelle o en la playa de la Bahía que designare». Por cada colono de más de 12 años, varón o mujer, Pérez abonaría 50 patacones de plata al señor Pezzi — consignatario del barco — del modo siguiente: una cuarta parte del total a los 3 meses de la fecha en que fueran recibidos por él, otra cuarta parte a los 6 meses, otra a los 9 y la última a los 12. Los colonos de menos de 12 años serían reputados 2 por 1 y los de menos de dos años viajaban gratis. Quedaba exceptuado del pago si alguno de los colonos llegaba «gravemente enfermo», al menos hasta que mejorara y estuviera apto para trabajar. ${ }^{34}$

Los colonos quedaban obligados desde su salida de Canarias, ya que debían firmar un contrato ante un escribano en el que se expresaba su obligación de servir a Pérez o a cualquier otra persona a quien este traspasara su derecho, por el salario de 5 pesos mensuales, hasta satisfacer completamente el importe del pasaje. ${ }^{35}$

Los viajes tenían su productividad tanto de ida como de vuelta, ya que se aprovechaba la salida del puerto de Montevideo para enviar dinero, bienes, comunicaciones, por parte de los canarios que ya habían arribado a la ciudad. En el año 1840 se publicó un «aviso a los naturales de las islas Canarias» donde se anunciaban las condiciones del viaje. El bergantín español Indio Oriental partiría de Montevideo para las Canarias en abril de 1840 al mando de su capitán don Florencio Arata. Se admitían «pasajeros, encomiendas o belillos, cueros, dinero para entregar en las Islas, hacer contratos para conducir de allá pasajeros, si aquella autoridad lo permitiese». ${ }^{36}$

32 AGN, AP, AJMP, Caja 135, carpeta 2. Thul Charbonnier, 2016, 156.

33 Albelo, 1985, 367.

34 AGN, AP, AJMP, Caja 135, carpeta 2. Thul, 2016, 156.

35 Idem.

36 AGN, AP, AJMP, Caja 135, carpeta 4. 
Los pasajeros que se querían transportar de este país a aquellas islas debían abonar su pasaje antes de embarcarse «a razón de 150 pesos los de Cámara, y 100 pesos los de Combez». Los cueros «se recibirán viniendo bien desgarrados, aprensados y escrito en el interior el nombre de la persona a quien se remite y la Isla y lugares de su residencia abonando antes los derechos y flete acostumbrado». El dinero que quisiera remitirse para las islas se entregaría en el escritorio de Juan María Pérez, quien daba recibos interinos por las cantidades que recibiese «y a vuelta de viaje el Capitán Arata los rescatará con los recibos de las personas a quien les fuesen entregados los dineros en las Islas». Si por enfermedad, ausencia o cualquier otra causa no llegara a recibir el dinero la persona a quien se le remite, Pérez quedaba obligado a devolverlo íntegramente.

La particularidad de estos viajes era la posibilidad de que individuos que ya vivían en Montevideo contrataran el viaje de familiares desde las Canarias. Generalmente se trataba de la familia de colonos que habían viajado años o meses antes, que tras instalarse en su nueva ciudad, pagaban el viaje de sus mujeres e hijos desde las islas. Los contratos estipulaban que el costo del pasaje debía ser pagado al contado por quien se contrataba al momento del arribo a Montevideo. ${ }^{37}$

La responsabilidad de Pérez era aducida por los capitanes de los barcos que se dirigían a él para responsabilizarlo del bienestar de los recién llegados: «sírvase usted proteger la referida expedición a fin de que por este medio logre un buen resultado de ella, advirtiendo a usted que dichos pasajeros son todos hombres robustos con buenas familias, útiles en la labranza y aptos para toda clase de trabajo». ${ }^{38}$

Las particularidades del viaje desde Europa hacían que en la mayoría de los casos fuera necesaria una escala en Río de Janeiro. En agosto de 1836 se especificaba un contrato mediante el cual el capitán Onorato Faracio, del buque sardo Dido, se obligaba a trasladar para Montevideo a cien colonos de las islas Canarias, venidos a Río de Janeiro en el bergantín español Libertad, a razón de 20 patacones por cada mayor de edad. Llegado a Montevideo se entregarían los colonos a Pérez. La situación se repitió en setiembre del mismo año cuando se contrató a «Pedro Smith, capitán del Escuna Oriental, para el traslado de 46 a 50 colonos desde Río a Montevideo venidos de las Islas Canarias». ${ }^{39}$

37 Idem.

38 AGN, AP, AJMP, Caja 136, carpeta 6.

39 Ibidem, carpeta 4. 
Los contratos no involucraban solamente a Pérez y su consignatario, sino que los colonos intervenían directamente en las negociaciones. Un contrato de colonos del bergantín Libertad fechado en 1837 en la bahía de Montevideo, señalaba:

Decimos nosotros los abajo firmados pasajeros que somos del bergantín español Libertad que arribó a Rio de Janeiro desde donde hemos sido conducidos a este puerto en el bergantín argentino Bella Juanita que por la presente nos obligamos a satisfacer a Juan María Pérez, además del flete que le adeudamos desde Lanzarote, como dueño de la expedición, los gastos que hemos hecho en el Janeiro.

\section{Se estipulaba luego que le pagarían a Pérez}

con nuestro trabajo personal regulado a 5 pesos mensuales cada uno de los hombres de trabajo, pues el de los muchachos queda a su criterio arreglarlo conforme a sus aptitudes, debiendo nuestras mujeres e hijas permanecer en nuestra compañía, y todos sin separarnos de la casa que nos recibe hasta que acabemos de satisfacer totalmente las cantidades que declaramos adeudar, o se nos contrate con otro patrono a cuya casa pasaremos en la misma conformidad y bajo las propias condiciones que lo estamos en esta; sin que para ello sea precisa la intervención de la policía que ahora autorizará la presente, ni de otro Juez alguno, pues a ello no hemos de oponer la menor resistencia. ${ }^{40}$

Las obligaciones de Pérez eran suministrarles el alojamiento, la manutención diaria (carnes, verduras, legumbres y fariñas) y adelantarles el dinero que necesitaran para comprar ropa o costear curas de enfermedades.

La especificidad del contrato era tal que se estipulaba de antemano incluso el salario que percibirían los colonos al integrarse a la actividad laboral. La particularidad estaba en que las mujeres trabajarían pero no recibirían a cambio de eso más que lo necesario para su manutención y debían permanecer junto a su familia.

El archivo de Pérez cuenta con varias docenas de contratos firmados por los colonos. Hacían referencia a los nombres de los contratantes, a las obligaciones que asumían, al monto de la deuda por el pasaje y a cómo la pagarían. Se incluía también unas líneas acerca de la imposibilidad de los colonos de desligarse de sus obligaciones y que en caso contrario, se daría intervención a la policía. Las formas de saldar la deuda eran varias. Algunos de los contratos estipulaban que los colonos se dedicarían al trabajo agrícola y el pago lo harían a través de las ganancias obtenidas por la cosecha de trigo que operaba como una especie de «seguro de pago». ${ }^{41}$

40 Idem.

41 Ibidem, carpeta 7. 
Luego de recibidos por Pérez, los colonos eran remitidos a diferentes propietarios que se obligaban a pagar una suma mensual a cambio de contar con el trabajo de las familias canarias. El accionar policial es presentado como contrapartida del cumplimiento del contrato por parte del colono. La policía era la fuerza que intimaba a que los migrantes cumplieran sus contratos, por lo que la acción del gobierno era fundamental para el funcionamiento de esta operativa. La policía había sido creada en 1827 bajo la denominación de «Policía Provincial» y luego de que en 1826 se dispusiera que tras la supresión de los cabildos la función policial estuviera a cargo de los comisarios departamentales. Fue regularizada y uniformizada por ley del 18 de diciembre de 1829, creándose el cargo de jefe político y de policía de cada departamento además del ya existente jefe de policía del Estado (creado por ley de agosto de 1829). ${ }^{42}$

Los contratos también eran firmados directamente entre los colonos y Pérez, como es el caso de un pasajero venido de las Canarias en la polacra española Bella Julia quien se «obligó a pagar al señor don Juan María Pérez, como consignatario de dicha expedición la cantidad que resulte adeudar según la contrata que tengo celebrada en dicha isla». El escrito se cerraba con la mención a que en caso de incumplimiento del pago de la deuda la familia canaria debía ponerse a disposición de Pérez. ${ }^{43}$

\section{La «venta» de la mano de obra en Montevideo}

Si bien buena parte de los colonos arribados quedaban a la orden del propio Pérez y los empleaba en sus diferentes actividades productivas y comerciales, otros eran «alquilados» para que se integraran como mano de obra en otras actividades. La evidencia más clara de que los colonos eran traídos con la intención de que fueran «alquilados» como mano de obra a quien los solicitara, es una nota enviada por Juan María Pérez al editor del diario El Universal que expresaba:

Familias Canarias han llegado a este puerto desde el de Buenos Aires con el objeto de contratarse para el servicio de cualquiera establecimiento, todas ellas tienen hombres de trabajo y pocas mujeres, y también se contratan solteros; el que necesitase de unos u otros ocurra al escritorio de Juan María Pérez. Montevideo, 22 de enero de $1838 .{ }^{44}$

42 Victoria Rodríguez, 2005, 212.

43 AGN, AP, AJMP, Caja 136, carpeta 7.

44 Ibidem, carpeta 6. Thul Charbonnier, 2016, 156-157. 
Uno de los casos en cuestión es el de Pablo Ordóñez. Este se obligó a satisfacer a Juan María Pérez diez pesos mensuales por los jornales de Bartolomé Martín y Salvador Martín, pasajeros del Bella Julia: «y en caso que no me conviniese que continuasen en mi servicio, se los entregaré a dicho Pérez en su casa». Un documento fechado meses más tarde señala la devolución por parte del hijo de Ordóñez de un nuevo colono llamado Eugenio, así como del contrato firmado con Pérez, advirtiéndole que «el colono Bartolo se halla bastante atacado de unas fiebres malignas, y lo estoy haciendo asistir lo mejor que me es posible». ${ }^{45}$

Los colonos se «alquilaban» para conseguir el dinero suficiente para pagar el costo de su pasaje o se ponían bajo las órdenes de quien se hiciera cargo de este pago. Tal es el caso de Valentín Tobal quien se obligó a pagar a Pérez lo adeudado por pasaje de Isidro Oliva y Domingo Figueras a quienes tenía empleados en su panadería. Agregaba que en caso de que «estas familias no les acomodase continuar en mi servicio, a que los tengo destinados, o a mí no se me acomodase tenerlos los presentaré en la casa de dicho Pérez y quedaré exento de este compromiso, pero de ningún modo antes de verificarlo». ${ }^{46}$

Otro aviso, de 1843, relataba la situación de una canaria ofrecida por su patrón:

Aviso. El que se interese en una sirvienta canaria, colona de 19 á 20 años de edad, solamente resta en la casa donde está, la mitad de su pasage; es de un servicio regular y de muy buena conducta: el que se interese en ella puede ocurrir calle del porton de la esquina de la Buena Vista 3 cuadras para fuera sobre mano derecha en la pulperia. La persona que la tiene se desase de ella por tenerse que ausentar del pais. ${ }^{47}$

Aunque quedaran bajo el control de otro individuo, su libertad seguía estando limitada. Juan Moreno se obligaba a «no desprenderse» de la familia de José Falero integrada por nueve personas, «ni dejarla salir de ningún modo de mi cuidado sin de ello dar parte y conocimiento al mencionado Pérez, quien ostenta derecho a que por ella le sea satisfecho el pasaje que hicieron en el bergantín Libertad de Islas Canarias a Río de Janeiro, por ser de su propiedad». ${ }^{48}$

45 AGN, AP, AJMP, Caja 136, carpeta 7.

46 Idem.

47 «Aviso», El Nacional, Montevideo, 1 de marzo de 1843.

48 AGN, AP, AJMP, Caja 136, carpeta 4. 
El sistema dotaba de mano de obra a los empleadores que la reclamaban, a cambio de la coacción a la que quedaban sometidos estos inmigrantes canarios, que solo lograrían su «libertad» si conseguían saldar su deuda.

\section{La deuda de los colonos y sus consecuencias}

Como señala Juan Oddone, este sistema «basado en la explotación del inmigrante que adeudaba el pasaje» estuvo vigente incluso hasta la década de 1870, según distintos testimonios consulares..$^{49} \mathrm{La}$ deuda generada era el principal elemento de la coacción ejercida sobre los colonos quienes eran forzados a integrarse al mercado de trabajo, tanto en Montevideo como en sus alrededores, siendo obligados a permanecer en el sistema hasta saldarla.

Según las fuentes notariales españolas consultadas por Albelo, el pago del pasaje debía realizarse al llegar al puerto de Montevideo.$^{50}$ Esto podría explicarse por la presencia de un intermediario, que pagara la deuda al responsable del viaje y a quien pasara a deberle el colono cuyo pasaje se abonaba a su arribo al puerto.

Dada la información sobre pagos mensuales de los colonos venidos a Montevideo en el barco Bella Julia, no queda claro si eran ellos mismos los que se hacían cargo de su deuda o si pasaba a ser responsabilidad de quien contrataba sus servicios.

La cuestión surge de identificar pagos mensuales de más de cien pesos, como por ejemplo los 180 pesos abonados por Siderio Carrión en junio de 1838 o los 210 pagados por Agustín y Pedro Morales en febrero de 1839. ${ }^{51}$ ¿Cómo alguien que recibía un salario de cinco pesos mensuales podía abonar 180 para saldar la deuda? Es evidente que en estos casos aquellos que contrataban como trabajadores a estos colonos abonaban el dinero requerido por Pérez, por lo que había una especie de transferencia de la deuda, ya que el colono ahora pasaba a deberle ese dinero a quien lo empleaba y lo pagaría con su propio trabajo.

Pero la fuente nos permite hacer nuevas consideraciones. Si bien es evidente que un colono no podía abonar cantidades tan grandes para saldar la deuda, tampoco se entiende que pudieran pagar 12 pesos si percibían

49 Oddone, 1966, 106.

50 Un registro notarial fechado en marzo de 1838 en Las Palmas de Gran Canaria estipulaba que la deuda «la satisfarán el día de su llegada al citado puerto de Montevideo, pudiendo compelérseles a ello ante las autoridades, y sin poder alegar ni admitírsele ninguna clase de excepción ni excusa de que pretenda valerse para eludir el cumplimiento de esta inviolable condición». Albelo, 1985, 372.

51 AGN, AP, AJMP, Caja 1, carpeta 7. 
apenas cinco por su trabajo. Esto nos obliga a cuestionarnos si la remuneración estipulada en el contrato era real y si estos colonos percibían el salario habitual en la época más allá de su condición.

A esta hipótesis, que consideramos la más probable, se adhieren varios de los casos encontrados. A través de un contrato, Pérez se comprometió a darle trabajo de albañil al colono Juan Arronga a cambio de 17 pesos mensuales más la comida. Por su parte el colono se obligaba a servirle sin separarse del trabajo y a no pedirle aumento de jornal. Luego de transcurrido el año inicial y según su comportamiento, Pérez podría pagarle un adelanto de su jornal y ofrecerle continuar con el servicio. ${ }^{52}$

Otro ejemplo es del año 1841 cuando los hermanos Ortega se comprometían a llevar a dos colonos canarios a su establecimiento de matadero «designándoles el salario de 15 pesos mensuales». También don Carlos García se obligó a llevar a otros dos a su establecimiento de saladero «pagándoles a razón de 13 patacones y también se compromete a mantenerlos y darles razón de galleta». ${ }^{53}$

De acuerdo a los contratos firmados por los colonos antes de viajar hacia Montevideo, los hombres recibirían cinco pesos mensuales por su trabajo y las mujeres no recibirían pago alguno. Si se comparan estos salarios con los datos sobre remuneraciones en la época se puede comprobar que estaban muy por debajo de los salarios pagados en la ciudad en distintas actividades.

Una mujer esclavizada podía recibir 6 pesos mensuales si trabajaba para una persona que no fuera su amo (la plata, la mayor parte, se la quedaba el amo) y un hombre esclavizado podía recibir, dependiendo de su tipo de trabajo, entre ocho y diez pesos de conchabo mensual en la década de $1830 .{ }^{54}$

El archivo de Pérez también brinda datos acerca de los salarios abonados en el trabajo de saladero. Dos peones contratados en el año 1837 recibieron 10 y 15 pesos mensuales por sus tareas. A esto se agregaba el tabaco y la vestimenta que les proporcionaba el propietario como parte del pago. ${ }^{55}$

Si dejamos la esfera privada y comparamos el salario que recibirían los colonos con los pagos del ámbito público la diferencia sigue siendo notable. Se trata de los salarios de la policía de Montevideo entre 1841 y 1857 . El único salario mensual que se equipara con el que recibían los colonos canarios es el del trabajador que realizaba la limpieza en la escuela de la ciudad.

52 AGN, AP, AJMP, Caja 136, carpeta 6.

53 AGN, AGA, Ministerio de Gobierno y Hacienda, 1841, Caja 934.

54 Borucki et al., 2004, 200-202.

55 AGN, AP, AJMP, Caja 138, carpeta 1. 
Los peones del cementerio, que podrían ser definidos como trabajadores no calificados, recibían dos veces más que los colonos que aquí estudiamos. ${ }^{56}$

Surge también la pregunta de si a aquellos que contrataban la mano de obra de estos colonos mediante un contrato con Pérez no les convenía más hacerse cargo ellos de la deuda y lograr con eso contar con mano de obra disponible por un tiempo prolongado, lo que no era tarea sencilla en un contexto de escasez de mano de obra y por tanto de altos salarios.

Si cruzamos las fuentes logramos corroborar que tanto los colonos como quienes los contrataban cumplían con sus obligaciones con Pérez. Uno de los casos es el del colono José Joaquín Pérez y Ramón de las Carreras, siendo este último quien se compromete a abonar el pasaje del primero y su familia, que ascendía a 282 pesos. Cruzando estos datos con la rendición de cuentas entre De las Carreras y Juan María Pérez se comprueba que efectivamente el primero abonó dicha suma en agosto de 1838. Este documento permite además comprobar que el atraso en los pagos generaba intereses a favor de Pérez que se sumaban a la deuda original. ${ }^{57}$

La deuda obligaba a los colonos a trabajar hasta saldarla o de lo contrario ponerse a las órdenes directas de Pérez y trabajar para él. Las formas de pagar eran varias y las fuentes revelan que las posibilidades de los colonos variaban mucho, obteniendo algunos de ellos más «libertad» que otros para escoger sus trabajos. Uno de los casos es el de Juan Pérez quien en mayo de 1839 envió una carta a Juan María Pérez diciendo haber sido pasajero de la fragata Bella Julia él y su familia y que se obligaba a pagarle 60 pesos de la próxima cosecha de trigo que iba a sembrar en terreno de don Joaquín Valdovino en Barros Blancos, a cuenta de su pasaje y el de su familia. Agregaba que en caso de no poder cumplir con dicho pago, se presentaría en la casa de Pérez y trabajaría para él. ${ }^{58}$

Tomás de León, otro canario arribado con su familia en el mismo barco, recibió la autorización de Pérez para «salir con mi familia a buscar mi subsistencia por el término de 14 meses», ya que se encontraba en una situación particular desde su arribo al puerto y no había pagado nada de lo adeudado por estar enfermo y no poder dedicarse a ningún tipo de trabajo. Agregaba que solo tenía hijos pequeños y por lo tanto tampoco estos se podían hacer cargo de salir a trabajar para pagar la deuda. ${ }^{59}$

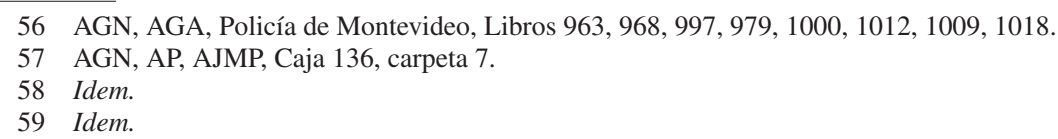

58 Idem.

59 Idem. 
La deuda generaba tal obligación con Pérez que este no dudaba en reclamar al juez del crimen por la libertad de tres colonos apresados que le adeudaban aun su pasaje: «Me presento y digo: que han sido aprehendidos por algunos desordenes y existen en el Juzgado de la Capital 3 colonos que me adeudan el pasaje, uno de ellos es José Guadalupe, padre de los otros dos Manuel y Francisco». Tras asegurar que ya se había comprobado que estos no eran criminales solicitó que se los liberara para que pudieran continuar con su trabajo y ofreció incluso pagar una fianza para la liberación en caso de que fuera necesario. ${ }^{60}$

Con la misma intención, de recuperar su dinero invertido en el arribo de los colonos, el apoderado de Pérez se presenta ante la justicia esta vez reclamando que la viuda de Manuel Coello, Sebastiana Bermúdez, le era deudora de 240 patacones por el pasaje de su familia «y además de los gastos que ha ocasionado y para las enfermedades de su marido». Se la acusaba de fugarse de la casa de Pérez sin su consentimiento por lo que se solicitaba que se la remitiera a esta familia nuevamente. ${ }^{61}$

\section{Un escenario difícil}

Los colonos arribados bajo este sistema migratorio no solo se encontraban con una deuda que pagar sino también con un difícil escenario para integrarse a la sociedad montevideana. Varias son las situaciones que dan cuenta de esto.

En 1835 se denunciaba en el libro copiador de notas de la policía de Montevideo la situación de una «porción de personas» mendigando por las calles, entre las que se destacaba la presencia de «canarias, que con el título de pordioseras transitan y entran en las casas, haciendo vivas instancias para que se les dé limosna». Debido a que la reglamentación prohibía mendigar, excepto con orden policial, se disponía que toda persona que se encontrara en estas condiciones fuera conducida a la policía del departamento. ${ }^{62}$

Los libros de entrada y salida de presos del período 1834-1836 muestran que solamente tres individuos identificados como «canarios» fueron apresados durante esos años. Debe tenerse en cuenta que el registro del

60 AGN, AP, AJMP, Caja 137, carpeta 1.

61 AGN, AP, AJMP, Caja 136, carpeta 7.

62 AGN, AGA, Policía de Montevideo, Libro copiador de notas, 946. 
origen del apresado, no siempre se hacía con precisión. En el mismo libro se identifican a algunos con los genéricos «extranjeros», «españoles» y «europeos». De aquellos tres, Juan Martínez y Pedro Martínez fueron enviados a prisión por Juan María Pérez en abril de 1836 por haber abandonado su trabajo, faltando así a su contrato. Pérez solicitaba se los remitiera a los trabajos públicos, aunque fueron dejados en libertad. ${ }^{63}$

Otro caso de intervención policial ocurrió en 1840 cuando Juan Iturbe presentó un escrito ante el juez del crimen de la ciudad. Allí señalaba que en la estancia de un vecino encontró a Juan, un colono canario que «pertenecía» a una familia que había pagado por la deuda de su pasaje, trabajando en un corral de piedra. Considerando que se encontraba «fugado», le pidió que volviera a sus trabajos, tras lo que «se apersonaron otros, diciéndome que aquel canario no había de volver a mi casa, que nada me debía». Tras la discusión, se inició una pelea con cuchillo y «pistola vacía», resultando Iturbe con varias puñaladas «que se observan en la chaqueta que vestía». El escrito finaliza con la solicitud de que el agresor fuera a prisión y que además pagara por los gastos y perjuicios causados. ${ }^{64}$

Juan Solari, el acusado, presenta al mismo juzgado, días más tarde, una comunicación donde detalla haber llegado a un arreglo con Iturbe para abonarle la cuenta por gastos por la herida que le causó en la estancia, que ascendía a 60 pesos. A cambio, este desistía de iniciar toda acción contra él. La suerte corrida por el colono que inició la discusión se desconoce. No obstante, podría creerse que dada la resolución del caso a favor de Iturbe, el canario debió regresar con este o al menos saldar su deuda. ${ }^{65}$

Pero además de las situaciones laborales conflictivas, la precaria situación económica y el peso de la deuda, los colonos debieron enfrentarse a otra dificultad: la militarización desde el comienzo de la llamada Guerra Grande (1838).

La ley de Guardia Nacional de 1835 exoneraba del servicio militar a los extranjeros ${ }^{66}$ pero para que esto se cumpliera era necesaria la presencia de agentes diplomáticos en el país que resguardara los derechos de aquellos. En caso contrario, como el de los españoles hasta 1845 cuando arribó

63 AGN, AGA, Policía de Montevideo, Libro de presos, 944.

64 AGN, AP, AJMP, Caja 137, carpeta 5. Thul Charbonnier, 2016, 161.

65 Thul Charbonnier, 2016, 161-162.

66 La Guardia Nacional fue creada el 1 de junio de 1835 para «suplir la falta del Ejército de línea para defensa y seguridad del Estado»; en su capítulo cuarto, la ley 90 señalaba que quedaban fuera del alistamiento «los extranjeros» entre otros. Armand-Ugón, 1930, $24-27$. 
Carlos Creus, la situación de los colonos estaba casi igualada a la de los nacionales. ${ }^{67}$

Fueron exonerados aquellos que «empleados en labores de labranza y establecimientos industriales, se hallan adeudando su pasaje». En 1842 se abrió en la policía un libro de colonos para registrar a los que quedaban exceptuados del servicio militar, a quienes se le daba una papeleta que acreditara su condición en la que debía contar el contrato entre el patrón y el colono. ${ }^{68}$

Apenas unos meses después, y ante la urgencia del avance de la guerra, este decreto fue derogado. Los canarios de entre 14 y 45 años debían ser reunidos, clasificados y enrolados en el Batallón de Infantería N. ${ }^{\circ} 6$ durante un año. No obstante, las autoridades declaraban que ningún canario se había presentado, a lo que se sumaba el reclamo de los acreedores de su deuda o de sus patrones, a quienes se les quitaba su mano de obra. ${ }^{69}$

A pesar de la resistencia al enrolamiento, los canarios, como también españoles de otras regiones, formaron parte de diferentes divisiones del ejército de la defensa de Montevideo durante la Guerra Grande.

\section{Consideraciones finales}

Los años posteriores a la creación del Estado Oriental del Uruguay estuvieron pautados por un problema económico central: la escasez de mano de obra. Para enfrentarlo, tanto el Estado como los particulares, impulsaron dos tipos de medidas: la atracción de trabajadores extranjeros y el «disciplinamiento» de los brazos disponibles en el país. Ambas situaciones se caracterizaron por la coacción ejercida hacia los individuos, en un contexto de inexistencia de relaciones de trabajo plenamente libres.

El objetivo de este artículo fue analizar una de las experiencias de atracción de inmigrantes: la de los colonos canarios. Como se pudo comprobar con la bibliografía analizada, el uruguayo no es un caso aislado sino que este tipo de inmigración ocurrió en varias regiones de América hacia mediados del siglo XIX.

Se realizó un estudio de las empresas de colonización emprendidas por el montevideano Juan María Pérez, uno de los principales contratistas

67 Etchechury-Barrera, 2015, 121.

68 AGN, AGA, Policía de Montevideo, Libro de adeudo de los pasajes de colonos, 967.

69 Etchechury-Barrera, 2015, 128. 
navieros de la época. Los inmigrantes canarios arribados al puerto de Montevideo durante la década del treinta se integraban al mercado de trabajo mediante un contrato que los obligaba a ocuparse hasta saldar la deuda de su pasaje. La policía podía intervenir en caso de que los colonos no cumplieran con lo estipulado, obligándolos a ponerse nuevamente bajo las órdenes de quien se había hecho cargo de su deuda. La participación de la policía era fundamental para la pervivencia de este sistema ya que era la que permitía, mediante la coerción, el cumplimiento de los contratos. Los colonos no eran obligados a viajar desde Canarias, la coacción no estaba en esta etapa del proceso sino una vez arribados a Montevideo, cuando eran sometidos a un estricto control privado y policial para que cumplieran con sus obligaciones.

A través de la bibliografía disponible, se comprobó que los empresarios privados tuvieron gran influencia en cuanto a los proyectos de colonización que eran aprobados o no por el Estado para ser ejecutados. La intervención del Estado era clave, no solo en la aceptación de los proyectos sino que, a través de la policía, funcionaba como garantía de que las condiciones del contrato se cumplieran asegurando a los propietarios inversores el rédito económico que buscaban. La importancia de estas empresas no estaba tanto en los beneficios en dinero que generaban sino más bien en que aumentaban los brazos disponibles y bajo un sistema en el cual los trabajadores no podían negarse a trabajar, aunque en la práctica se constataran fugas e incumplimientos de contratos.

El artículo pretende aportar en relación al conocimiento histórico de un tipo particular de inmigración. Su particularidad está dada por la situación de coacción a la que estaban sometidos los extranjeros arribados al país. Es posible hablar de este como un régimen de «semi-esclavitud».

La evidencia empírica aportada da cuenta de que la situación que enfrentaban los colonos tras su arribo era compleja. Muchos quedaban inmersos en la pobreza, que se sumaba a la situación de dominación a la que eran sometidos mientras adeudaran su pasaje. Fueron, además, blanco del enrolamiento militar ante el estallido de la Guerra Grande. No obstante, también fue posible encontrar casos donde queda en evidencia la resistencia, manifestada a través de la fuga e incluso el no pago de su deuda. 


\section{Referencias bibliográficas}

Albelo Martín, María Cristina, «Trabajadores canarios en América: algunos ejemplos de contratas», en Morales Padrón, Francisco (coord.), V Coloquio de Historia Canario-Americana (1982), Cabildo Insular de Gran Canaria, 1985, v. 1, 341-406.

Altman, Ida, «Emigrants and Society: An Approach to the Background of Colonial Spanish America», Comparative Studies in Society and History, 30, 1, 1988, 170-190.

Altman, Ida y Horn, James J. (eds.), «To Make America»: European Emigration in the Early Modern Period, Berkeley, University of California Press, 1991.

Armand-Ugón, Enrique, Compilación de Leyes y Decretos, 1825-1930, Tomo 2 (1835-1843), Montevideo, Imprenta Nacional Colorada, 1930.

Bentancur, Arturo A., «Políticas migratorias en España y Uruguay», en Zubillaga, Carlos (ed.), Españoles en el Uruguay. Características demográficas, sociales y económicas de la inmigración masiva, Montevideo, Universidad de la República, 1997, 9-52.

Carnero Lorenzo, Fernando y Barroso Ribal, Cristino, «Canarias-Uruguay: una dimensión poco conocida del movimiento migratorio isleño», en Viejas y nuevas alianzas entre América Latina y España: XII Encuentro de Latinoamericanistas Españoles, s.1., España, CEEIB, 2006, 45-70.

Cerdeña Armas, Francisco Javier, Colonos majoreros en la expedición de Francisco Morales al Río de la Plata: 1833, Puerto del Rosario, Cabildo Fuerteventura, 2002.

De Cristóforis, Nadia Andrea, «Políticas y prácticas migratorias: los flujos de gallegos y asturianos a Buenos Aires (1840-1860)», Revista de Indias, LXVIII, 244, Madrid, 2008, 85-114.

De Paz Sánchez, Manuel y Hernández González, Manuel, La esclavitud blanca. Contribución al estudio del inmigrante canario en América. Siglo XIX, Tenerife, Centro de la Cultura Popular Canaria, 1993.

Etchechury-Barrera, Mario, «De colonos y súbditos a "ciudadanos en armas". Militarización y lealtades políticas de los españoles residentes en Montevideo, 1838-1845», Revista Universitaria de Historia Militar, 8, 2015, 119-142.

Fernández Saldaña, José María, Diccionario uruguayo de biografías 1810-1940, Montevideo, Amerindia, 1945.

Galenson, David W., «The Rise and Fall of Indentured Servitude in the Americas: An Economic Analysis», Journal of Economic History, 44(1), 1984, 1-26.

Gelman, Jorge, «El fracaso de los sistemas coactivos de trabajo rural en Buenos Aires bajo el rosismo, algunas explicaciones preliminares», Revista de Indias, LIX, 215, Madrid, 1999, 123-141. 
Grubb, Farley, «The Market for Indentured Immigrants: Evidence on the Efficiency of Forward-Labor Contracting in Philadelphia, 1745-1773», The Journal of Economic History, 45, 4, 1985, 855-868.

Lamas, Andrés, "Noticias Estadísticas de la República Oriental del Uruguay" [1850], Revista del Instituto Histórico y Geográfico del Uruguay, VI-1, Montevideo, 1928, 33-194.

Martínez Díaz, Nelson, «La inmigración canaria en Uruguay durante la primera mitad del siglo XIX una sociedad para el transporte de colonos», Revista de Indias, 151-152, 1978, 349-402.

Martínez Díaz, Nelson, «La emigración clandestina desde las Islas Canarias al Uruguay. Formas de incorporación social. Ensayo de estudio cuantitativo», V Coloquio de Historia Canario-Americana (1982), Cabildo Insular de Gran Canaria, Las Palmas, 1985, 249-313.

Martínez Díaz, Nelson, «Inmigración canaria y expansión de la frontera agrícola en Uruguay: 1830-1880», VIII Coloquio de Historia Canario-Americana (1988), Cabildo Insular de Gran Canaria, Instituto de Cooperación Iberoamericana, Las Palmas, 1988, 347-368.

Montero Bustamante, Raúl, Juan María Pérez, 1790-1845, Montevideo, Barreiro y Ramos, 1945.

Morgan, Edmund, Esclavitud y libertad en los Estados Unidos. De la colonia a la independencia, Buenos Aires, Siglo XXI, 2009.

Musso Ambrosi, Luis A., «Los canarios en el Uruguay, 1724-1756», IV Coloquio de Historia Canario-Americana (1982), Las Palmas, Cabildo Insular de Gran Canaria, 1984, 452-454.

Musso Ambrosi, Luis A., «Historiografía y bibliografía sobre los canarios en Uruguay», VI Coloquio de Historia Canario-Americana (1984), Las Palmas, Cabildo Insular de Gran Canaria, 1986, 883-1093.

Musso Ambrosi, Luis A., Canarios en Uruguay (1830-1859), Canarias, Cabildo Insular de Gran Canaria, 1986.

Musso Ambrosi, Luis A., «Canarios en Uruguay (1830-1850)», VII Coloquio de Historia Canario-Americana (1986), Las Palmas, Cabildo Insular de Gran Canaria, 1990, 419-489.

Musso Ambrosi, Luis A., «Peripecias de la colonización canaria en la Banda Oriental», IX Coloquio de Historia Canario-Americana (1990), Las Palmas, Cabildo Insular de Gran Canaria, 1992, 737-756.

Musso Ambrosi, Luis A., «Colonización canaria. Canarios en la Banda Oriental», Revista de la Biblioteca Nacional, 28, Montevideo, 1996, 15-162.

Oddone, Juan Antonio, La emigración europea al Río de la Plata: motivaciones y proceso de incorporación, Montevideo, Ediciones de la Banda Oriental, 1966.

Parsons, James J., «The Migration of Canary Islanders to the Americas: an Unbroken Current Since Columbus», The Americas, 39, 4, 1983, 447-481. 
Pivel Devoto, Juan E., Prólogo, en Bauzá, Francisco, Estudios sociales y económicos, Montevideo, Colección de Clásicos Uruguayos v. 140, 1972, VII-CLXI.

Real de Azúa, Carlos, El patriciado uruguayo, Montevideo, Editorial Asís, 1961.

Thul Charbonnier, Florencia, Coerción y relaciones de trabajo en el Montevideo independiente, 1829-1842, Tesis para obtener el título de Magister en Historia Rioplatense, Facultad de Humanidades y Ciencias de la Educación, Universidad de la República, Montevideo, 2014, inédita.

Thul Charbonnier, Florencia, «Entre la coacción y la resistencia. Prácticas asociativas de los trabajadores de Montevideo en la década de 1830», A Contracorriente, 14-1, NC State University, 2016, 148-172.

Victoria Rodríguez, José A., Evolución histórica de la policía uruguaya, Tomo 1, Montevideo, Biblos, 2005. 